\title{
Pleomorphic Adenoma of the Sublingual Salivary Gland: An Unusual Diagnostic Challenge
}

\author{
Stylianos Dalampiras ${ }^{a} \quad$ Dimitrios Andreadis $^{b}$ Apostolos Epivatianos ${ }^{b}$ \\ Leonidas Sakas ${ }^{c}$ Peter Stanko ${ }^{d}$ \\ Departments of ${ }^{\mathrm{a}}$ Oral and Maxillofacial Surgery and ${ }^{\mathrm{b}}$ Oral Medicine/Pathology, School of Dentistry, \\ Aristotle University of Thessaloniki, and 'Department of Histopathology, 'G. Papanikolaou' General Hospital, \\ Thessaloniki, Greece; 'Department of Oral and Maxillofacial Surgery, Faculty of Medicine, Comenius University, \\ Bratislava, Slovakia
}

\section{Key Words}

Salivary gland tumors $\cdot$ Pleomorphic adenoma $\cdot$ Sublingual gland

\begin{abstract}
Objectives: To describe a rare case of pleomorphic adenoma of the sublingual gland. Clinical Presentation and Intervention: An 80-year-old patient presented with a painless solid submucosal mass of 4 months' duration in the anterior floor of the mouth, appearing as a distinct homogeneous, radiolucent lesion in CT imaging. Histologic findings after complete removal were suggestive of a pleomorphic adenoma almost completely surrounded by a fibrous capsule. No recurrence was observed after a 12-month follow-up. Conclusion: This case showed the possibility of sublingual salivary gland tumors and highlighted the need to consider them when making a differential diagnosis of masses located in the floor of the mouth.

Copyright $\odot 2012$ S. Karger AG, Basel
\end{abstract}

\section{Introduction}

Salivary gland tumors are rare, representing 3.5-10\% of all head and neck tumors. Neoplasms of the sublingual salivary glands constitute $0.3-5.2 \%$ of all epithelial salivary gland tumors and approximately $1.5 \%$ of all carcinomas of major salivary glands $[1,2]$. The great majority, approximately $80-90 \%$ of the tumors that arise from the sublingual gland, are malignant $[3,4]$, whereas benign tumors such as pleomorphic adenoma are rarely reported [5-7]. In this case we describe an asymptomatic pleomorphic adenoma of the sublingual salivary gland.

\section{Case Report}

An 80-year-old patient was referred to the Department of Oral and Maxillofacial Surgery, School of Dentistry, Aristotle University of Thessaloniki, Greece, complaining of a painless swelling located in the floor of the mouth, causing minor discomfort. The duration of the swelling was 4 months and it was progressively enlarging. His medical history was free of any local or systemic diseases.

\section{KARGER \\ Fax +4161306 1234 \\ E-Mail karger@karger.ch}

www.karger.com
(2) 2012 S. Karger AG, Basel

$1011-7571 / 12 / 0213-0282 \$ 38.00 / 0$

Accessible online at:

www.karger.com/mpp
Dr. Andreadis Dimitrios

Department of Oral Medicine/Pathology, School of Dentistry

Aristotle University of Thessaloniki

GR-54124 Thessaloniki (Greece)

Tel. +30 231099 9538, E-Mail dandrea@ dent.auth.gr 
Fig. 1. Firm, solid, tumor-like lesion covered with normal mucosa in the anterior part of the floor of the mouth.

Fig. 2. Distinct radiolucent, homogeneous lesion in the area where normally the left sublingual gland lies (sublingual sulcus) (arrow).
1

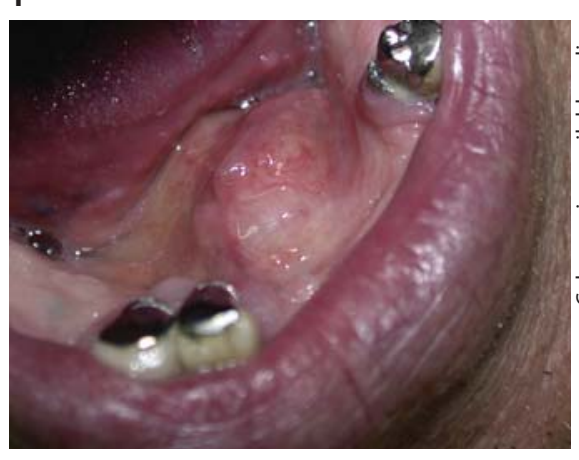

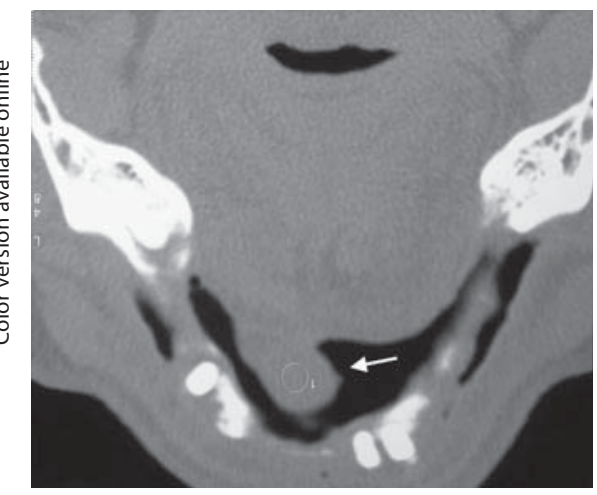
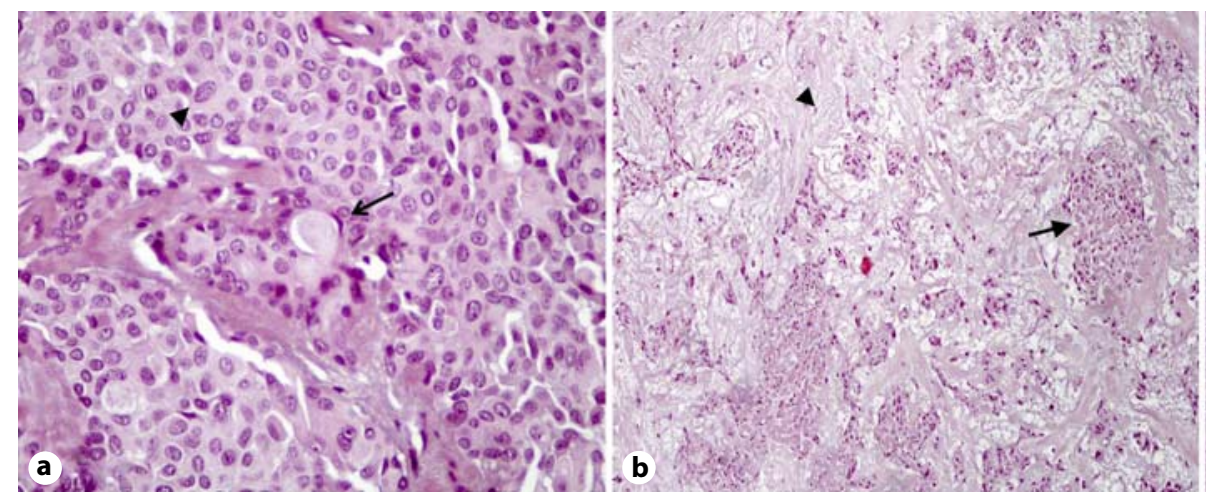

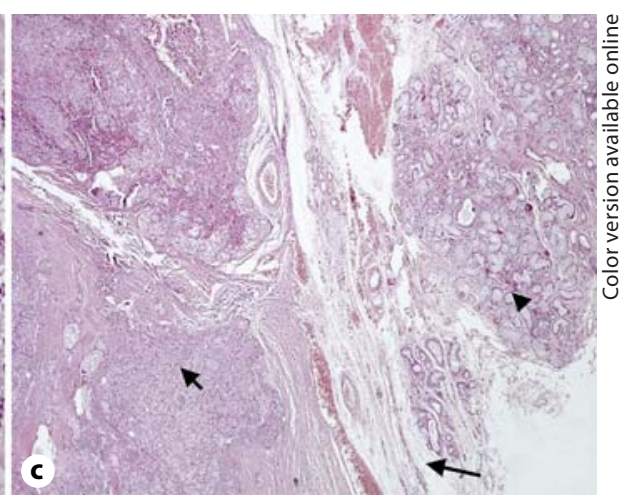

Fig. 3. a Large number of epithelial/myoepithelial-type neoplastic cells with low mitotic activity forming sheets, solid islands (arrowhead) and duct-like structures (arrow). b Small amount of myxoid stroma containing spindle-shaped and plasmacytoid cells (arrowhead), among neoplastic cell structures (arrow). c The tumor (small arrow) was almost completely separated from adjacent mucosa and minor salivary glands (arrowhead) by a fibrous capsule (large arrow).
The intraoral examination and palpation revealed a firm, solid-elastic, movable, tumorous lesion, measuring $2 \times 3 \mathrm{~cm}$ covered by normal mucosa located in the anterior part of the floor of the mouth beside the excretory duct of the left submandibular gland (fig. 1). Computed-tomography (CT) images showed a distinct radiolucent, homogeneous lesion extending anteriorly in the area where the left sublingual gland (sublingual sulcus) normally lies (fig. 2). Under local anesthesia, a complete surgical enucleation of the lobular tumor with an additional zone of adjacent normal tissue was performed intraorally. Histological examination showed a large number of epithelial/myoepithelialtype neoplastic cells with low mitotic activity forming sheets, solid islands and duct-like structures, as well as small amounts of myxoid stroma containing spindle-shaped and plasmacytoid cell. The tumor was almost completely surrounded by a fibrous capsule and the margins were free of neoplastic cells (fig. 3a-c). These findings were suggestive of a pleomorphic adenoma of the sublingual gland. After 12-month follow-up no recurrence was observed.

\section{Discussion}

Sublingual salivary gland tumors are rare compared with other major glands with a reported ratio of 1 case of sublingual tumor to 100 parotid tumors [1] or less [7]. The great majority of these tumors are malignant and few benign cases of pleomorphic adenomas, myoepitheliomas and oncocytomas have been described [7-9]. Sublingual benign tumors present as asymptomatic swelling of the floor of the mouth under the tongue, causing discomfort and difficulty in dental prosthesis retention [10], and may be incidentally discovered by a dentist, as happened in our case.

The differential diagnosis of sublingual gland tumors may include other salivary gland tumors of submandibular/minor salivary glands, or even other non-salivary gland tumors like lymphomas, non-neoplastic entities of salivary glands such as ranulas, retention cysts, sialoli- 
thiasis, sialadenitis, and cystic lesions of the floor of the mouth such as dermoid cysts.

Early total surgical resection of the sublingual gland and its neoplastic mass in normal margins for benign tumors is the treatment of choice to avoid recurrences. The excision may possibly be accompanied by selective neck dissection and radiotherapy for malignancies. The histologic examination of the lesions is necessary not only to establish the diagnosis but also for the better management of the surrounding tissues.

Depending on the tumor size and location, the total resection may become quite complex especially for malignancies due to the close proximity of the sublingual gland to the inner cortex of the mandible, the subman- dibular salivary gland and its duct, the lingual vessels and nerve, and the hypoglossal nerve $[8,10]$. In our case, clinical and CT imaging features indicated a close-to-surface, circumscribed, easily accessible tumor, and thus an intraoral total resection of the lesion was performed.

\section{Conclusions}

This case showed that sublingual salivary gland tumors, including pleomorphic adenoma, should be included in the differential diagnosis of masses located in the floor of the mouth with minimal or no symptoms.

\section{References}

$>1$ Eveson JW, Cawson RA: Salivary gland tumors: a review of 2,410 cases with particular reference to histopathological types, site, age and sex distribution. J Pathol 1985;146:5158.

$>2$ Spiro RH, Armstrong J, Harrison L, Geller NL, Lin S-Y, Strong EW: Carcinoma of major salivary glands: recent trends. Arch Otolaryngol Head Neck Surg 1989;115:316-321.

$>3$ Speight PM, Barrett AW: Salivary gland tumours. Oral Dis 2002;8:229-240.

4 Nagler RM, Laufer D: Tumors of the major and minor salivary glands: review of 25 years of experience. Anticancer Res 1997;17:701707.
5 Okura M, Hiranuma T, Shirasuna K, Matsuya T: Pleomorphic adenoma of the sublingual gland: report of a case. J Oral Maxillofac Surg 1996;54:363-366.

$\checkmark 6$ da Cruz Perez DE, Pires FR, Alves FA, Almeida OP, Kowalski LP: Sublingual salivary gland tumors: clinicopathologic study of six cases. Oral Surg Oral Med Oral Pathol Oral Radiol Endod 2005;100:449-453.

7 Zdanowski R, Dias FL, Barbosa MM, Lima RA, Faria PA, Loyola AM, Souza KCN: Sublingual gland tumors: clinical pathologic and therapeutic analysis of 13 patients treated in a single institution. Head Neck 2011;33: 476-481.
8 Sun G, Yang X, Tang E, Wen J, Lu M, Hu Q: The treatment of sublingual gland tumours. Int J Oral Maxillofac Surg 2010;39:863-868.

$\checkmark 9$ Tian Z, Li L, Wang L, Hu Y, Li J: Salivary gland neoplasms in oral and maxillofacial regions: a 23-year retrospective study of 6982 cases in an eastern Chinese population. Int J Oral Maxillofac Surg 2010;39:235-242.

10 Rinaldo A, Shaha EA, Pellitteri PK, Bradley, Ferlito A: Management of malignant sublingual salivary gland tumors. Oral Oncol 2004;40:2-5. 